\title{
A retextualização interlingual de fábulas: um estudo de caso
}

\section{The inter-lingual retextualization of fables: a case study}

\author{
Clarissa Rosas* \\ Heloísa Pezza Cintrão*
}

\begin{abstract}
Resumo: 0 presente trabalho, que constitui parte de uma pesquisa maior, apresenta um estudo de caso sobre uma fábula do espanhol Tomás de Iriarte, publicada em 1782 e traduzida à língua portuguesa em diferentes momentos ao longo dos séculos XVIII e XX. O artigo inicia tratando da formação do conceito de literatura infantil e da evolução histórica desse gênero, chegando à inserção da fábula na literatura infantil. A partir daí, apresenta o modelo descritivo de tradução proposto por Lambert e Van Gorp (2011[1985]) e o trabalho de Genette (2009[1987]) acerca dos paratextos editoriais, com vistas a esquematizar alguns pontos para análise. Em seguida, dá início ao estudo de caso, que analisa duas retextualizações interlinguais (espanholportuguês) da fábula "El Pato y la Serpiente" em relação a seu texto-fonte.
\end{abstract}

Palavras-chave: Fábulas; Literatura infantil; Paratextos editoriais; Tradução interlingual; Adaptação.

Abstract: This work, which is part of a major research, presents a case study on a fable of the Spanish author Tomás de Iriarte, published in 1782 and translated into Portuguese at different moments through the 18th and 20th centuries. Firstly, the paper addresses the arising of the concept of children's literature and the historic evolution of this gender, until the insertion of fable in children's literature. Then, it presents Lambert \& Van Gorp's (2011[1985]) descriptive translation studies model and Genette's (2009[1987]) work on paratexts, in order to lay out some points for analysis. Finally, it develops a case study on two inter-lingual retextualizations (Spanish-Portuguese) of the fable "El Pato y la Serpiente" towards the source text.

Keywords: Fables; Children's literature; Paratexts; Inter-lingual translation; Adaptation.

\footnotetext{
* Mestre em Estudos da Tradução pela Universidade de São Paulo e doutoranda em Letras na Universidade Federal da Paraíba. Contato: clarissa.rosas@usp.br.

** Docente do Programa de Pós-Graduação em Estudos da Tradução da Universidade de São Paulo e doutora em Letras pela Universidade de São Paulo. Contato: helocint@usp.br.
} 


\section{Introdução}

O que hoje consideramos literatura infantil nem sempre foi visto dessa forma. Antes de tudo, é preciso entender que o conceito de literatura infantil é situado historicamente, tendo-se desenvolvido lado a lado com o próprio conceito de infância, conforme discutido por Ariès (1981), Lajolo e Zilberman (1985). Em determinado período da história, que se estende até meados do século XVIII, a criança era vista como um adulto em miniatura, condição que aparece representada até mesmo em ilustrações da época. Nesse ambiente pouco favorável à percepção das particularidades da infância, as crianças participavam da vida adulta com poucas restrições - ou sem nenhuma delas. As mais variadas histórias que se contavam, quer fossem da tradição oral ou da literatura já registrada na recém constituída imprensa, chegavam a todos os públicos, inclusive ao infantil; assim, não havia temas censurados ou linguagem facilitada para os pequenos leitores.

Com as mudanças decorrentes da Revolução Industrial, que propiciaram uma reorganização da sociedade, houve também uma reestruturação da ordem familiar, na qual tipicamente o homem sai para trabalhar e a mulher fica em casa cuidando dos filhos. Nesse novo cenário, a infância começou a ser vista como uma fase especial da vida, e pouco a pouco foram se desenvolvendo bens de consumo voltados para o público infantil, como livros e brinquedos, além de áreas específicas da ciência, como a pediatria. No caso da literatura, foram apropriados gêneros como contos de fadas e fábulas que, por conterem elementos de fantasia e propósitos moralizantes, eram considerados de especial interesse para esse público -, bem como clássicos adaptados - o que se justifica pela preocupação de dotar crianças e jovens com textos adequados à sua formação. ${ }^{1}$

\footnotetext{
${ }^{1}$ Dentre esses, dedicaremos atenção especial às fábulas, que a princípio constituíam uma literatura oral e eram contadas sem o auxílio de um suporte físico, o que possivelmente era um dos fatores que contribuíam para que fossem produzidas em versos, facilmente memorizáveis. Posteriormente, com o advento da imprensa, os fabulários de diversos autores
} 
Assim, percebemos que há determinadas histórias hoje classificadas como literatura infantil que não surgiram com esse propósito específico, mas que a partir de determinado momento passaram a compor um repertório voltado para crianças. E, à medida que essa literatura foi se consolidando, desenvolveram-se também técnicas de adaptação literária para crianças ou jovens - tanto em traduções entre línguas quanto dentro de um mesmo idioma -, que incluíam adequação de conteúdo e simplificação da linguagem, além de toda a parte gráfica que envolve ilustrações, tipografia, diagramação etc. A literatura infantil hoje apresenta produtos dos mais diversos tipos (livro ilustrado, livro-álbum, livro-imagem, livro-brinquedo, entre outros) voltados para cada faixa etária, que introduzem os leitores ao universo da leitura e da literatura, explicam assuntos cotidianos de forma simplificada e estimulam a criatividade, entre outras funções que possam assumir.

O termo 'adaptação' é alvo de profusas discussões dentro dos Estudos da Tradução, que não o definem de forma única. Isso se deve ao fato de que toda tradução pode ser vista como uma adaptação, dada sua natureza recriadora e as necessidades de adequação que se manifestam em maior ou menor medida, a depender do caso. A presença de certo grau de adaptação em qualquer texto traduzido impediria, portanto, classificar determinados produtos como traduções e outros, como adaptações. Todavia, deixando um pouco de lado esse ponto de vista generalista, é possível enxergar a adaptação numa visão micro, como um dentre diversos procedimentos tradutórios, bem como numa visão macro, como uma estratégia global de reescritura de um texto-fonte (BASTIN 2009 [1997]).

Aqui, buscamos entender o que se adaptou nos textos selecionados, tendo em mente tanto essa visão macro da adaptação como uma estratégia global, que resulta em um texto-alvo (doravante, TA) não reconhecido como uma tradução do seu texto-fonte (doravante, TF), mas que mantém suas raízes nele; quanto a visão micro da adaptação como procedimento tradutório, que pode trabalhar determinados aspectos no TA com mais liberdade sem, com isso, afastá-lo tanto do TF ao ponto de que não se possa

foram registrados em papel e as fábulas passaram a assumir mais frequentemente o formato de prosa, em especial quando voltadas para o público infantil. 
mais reconhecê-lo como uma tradução. Buscamos entender, portanto, as estratégias globais e pontuais de adaptação dentro de retextualizações interlinguais.

Levando em conta que o propósito e o público-alvo nas diversas retextualizações de mesmos textos-fonte parecem ser chave para entendêlas, o presente estudo pretende conjugar uma perspectiva descritiva e uma funcionalista para investigá-las, sejam elas elaboradas com o propósito claro de atrair o público infantil ou não. A abordagem de análise para tratar desses pontos é o que investigaremos na próxima sessão.

\section{Referencial teórico}

O principal instrumental de análise escolhido foi o modelo descritivo de tradução literária proposto por Lambert e Van Gorp (2011 [1985]), combinado com trabalho de Genette (2009 [1987]) sobre paratextos editoriais.

O modelo proposto por Lambert e Van Gorp elenca quatro categorias de análise textual, por meio das quais se pode descrever e examinar estratégias tradutórias - considerando a tradução essencialmente como o "resultado de estratégias de seleção 'a partir' e 'dentro' dos sistemas de comunicação" (LAMBERT; VAN GORP 2011 [1985]:202). Uma série de questionamentos visa a determinar quais relações podem ter um papel na produção e no formato das traduções e quais podem ser observadas na descrição da tradução. Segundo os autores, o modelo compreende todos os aspectos funcionalmente relevantes de uma determinada atividade tradutória em seu contexto histórico, inclusive o processo da tradução, suas características textuais, sua recepção e aspectos sociológicos como distribuição e crítica da tradução.

0 esquema proposto diz respeito às relações entre texto-fonte $(\mathrm{T} 1)$, texto-alvo (T2), autor do texto-fonte (A1), autor do texto-alvo (A2), leitor do texto-fonte (R1), leitor do texto-alvo (R2), sistema do texto-fonte (S1) e sistema do texto-alvo (S2). "Todos os elementos desse esquema de comunicação são complexos e dinâmicos [...] [e] o elo entre a comunicaçãofonte e a comunicação-alvo não pode ser realmente previsto" (LAMBERT; VAN GORP 2011 [1985]: 199), já que se trata de uma relação aberta e são as 
prioridades do comportamento do tradutor que definirão sua natureza. Assim,

[c]omo toda tradução é o resultado de relações específicas entre os parâmetros mencionados no esquema, a tarefa do estudioso será estabelecer quais relações são as mais importantes. Entre as prioridades a serem observadas, destacam-se principalmente as traduções orientadas ao sistema-alvo (ou 'aceitáveis') e as traduções orientadas ao sistema-fonte (ou 'adequadas'). Porém os grupos de traduções 'aceitáveis' podem ainda mostrar características diferentes quanto às relações $\mathrm{T} 2$-.- $\mathrm{T} 1, \mathrm{~T} 2$-.- $\mathrm{A} 1$, ou T2 -.- R1. De um ponto de vista empírico, pode-se seguramente presumir que nenhum texto traduzido será inteiramente coerente em relação ao dilema 'adequado' versus 'aceitável'. (LAMBERT; VAN GORP 2011 [1985]:201)

Essa última consideração envolve, por exemplo, casos em que as características estilísticas de um texto traduzido estejam orientadas ao sistema-alvo, enquanto que suas referências socioculturais estejam voltadas ainda ao sistema-fonte. Essa dualidade 'adequado' versus 'aceitável' possibilita estudar o processo de tradução, o texto resultante dele e sua recepção "a partir de diferentes pontos de vista, de maneira macroestrutural ou microestrutural, focalizando em padrões linguísticos de vários tipos, códigos literários, padrões morais, religiosos ou outros não literários etc." (LAMBERT; VAN GORP 2011 [1985]:203).

No campo dos Estudos da Tradução, desde 1995 se conhece a distinção de Toury entre os princípios de adequação e aceitabilidade: aplicando-se o primeiro, o tradutor se concentra em características distintivas do original, como língua, estilo e elementos culturais, considerando como dominante o TF e sua máxima conservação; aplicando-se o segundo, o tradutor se volta para a produção de um TA com maior legibilidade, no qual a linguagem e o estilo estejam em harmonia com as convenções linguísticas e literárias da cultura receptora, considerando como dominante essa cultura e a função do texto dentro dela. Como resultado, uma tradução nunca vai ser totalmente adequada ou aceitável, mas tende a se apresentar como uma combinação dos dois princípios.

Com isso em mente, podemos ignorar noções tradicionais como fidelidade e qualidade tradutória, que via de regra são normativas e focadas no TF, para nos dedicarmos a uma análise funcional e semiótica. Assim, é 
possível desde já conjeturar algumas considerações. Primeiro, as fábulas são um típico gênero da "literatura universal" e, assim como os mitos e os contos de fadas, cumprem um papel no desenvolvimento de praticamente todas as literaturas, desde tempos remotos. No entanto, talvez tenham muitas vezes um papel periférico ou de menor prestígio no sistema, especialmente quando relacionadas à literatura infantil. Segundo, com relação a funções conservadoras ou inovadoras, pareceria que as fábulas tendem a cumprir funções conservadoras, não apenas do ponto de vista literário mas também nos sistemas de valores (ao veicular valores conservadores), dado seu caráter educativo e moralizante. Ainda, podemos fazer uma ponte com o comentário de Sanders (2006:45), que aponta que mitos, contos de fadas e folclore são um material tipicamente aberto a reformulações ao longo do tempo, o que propicia adaptações e apropriações de diferentes tipos. Apesar de a autora não mencionar as fábulas, reconhecemos a afinidade dos gêneros e, por conseguinte, estendemos o comentário.

Para a análise de traduções, o modelo de Lambert e Van Gorp (2011 [1985]:211-212) parte de aspectos mais gerais, passa por aspectos mais específicos e termina com aspectos mais amplos, que ultrapassam a descrição das traduções propriamente ditas. Para tanto, o modelo abrange: i) questões preliminares, que incluem título e página-título, presença ou ausência da indicação de gênero, nome do autor, nome do tradutor, metatextos (na página-título, no prefácio, nas notas de rodapé, no texto ou separado) e estratégia geral (tradução parcial ou completa); ii) macronível, que inclui a divisão do texto (em capítulos, atos, cenas, estrofes), título dos capítulos, relação entre os tipos de narrativa, diálogos, descrição, estrutura narrativa interna, estrutura poética; iii) micronível, que inclui seleção de palavras, padrões gramaticais dominantes e estruturas literárias formais (metro, rima), formas de reprodução da fala (direta, indireta, indireta livre), narrativa, perspectiva e ponto de vista, modalidade (passiva ou ativa, expressão de incerteza, ambiguidade), níveis de linguagem (socioleto, arcaico, popular, dialeto, jargão); e iv) contexto sistêmico, que inclui oposições entre micro e macroníveis e entre texto e teoria (normas, modelos), relações intertextuais (outras traduções e obras “criativas”), relações intersistêmicas (estruturas de gênero, códigos estilísticos). 
Essa análise deve levar a comentários finais sobre a categorização dos textos como tradução ou adaptação; sobre técnicas de adaptação adotadas, como redução ou ampliação; e sobre o público-alvo declarado ou inferido a partir desse estudo (utilizando, para isso, a análise de paratextos proposta por Genette), em relação com o público de Iriarte e o sistema de origem de seus textos.

No que diz respeito aos paratextos editoriais, Genette divide o campo em duas categorias: peritexto e epitexto. 0 peritexto é definido como a categoria espacial que se encontra "em torno do texto, no espaço do mesmo volume, como o título ou o prefácio, e, às vezes, inserido nos interstícios do texto, como os títulos de capítulo ou certas notas" (GENETTE 2009 [1987]:12). 0 epitexto é definido como "todas as mensagens que se situam na parte externa do livro: em geral num suporte midiático (conversas, entrevistas), ou sob a forma de uma comunicação privada (correspondências, diários íntimos e outros)" (GENETTE 2009 [1987]:12).

No presente caso, não nos propomos a localizar e analisar epitextos para as obras do corpus, e a análise paratextual deve se focar no nível do peritexto. A esse respeito, é de particular relevância a consideração de Genette acerca da questão de uma obra se encontrar inserida em uma coleção. 0 autor defende que essa inserção tem objetivos e significados, e mesmo a ausência de uma coleção é sentida pelo público. Segundo o autor,

[o] selo de coleção, mesmo sob essa forma muda, é, pois, uma duplicação do selo editorial, que indica imediatamente ao potencial leitor que tipo ou que gênero de obra tem a sua frente: literatura francesa ou estrangeira, vanguarda ou tradição, ficção ou ensaio, história ou filosofia etc. (GENETTE, op. cit.: 26).

Assim, o estudo apresentado apoia-se em um modelo descritivo para analisar duas retextualizações de uma fábula de autoria do espanhol Tomás de Iriarte, que viveu no século XVIII e divide com Samaniego o posto de principal fabulista da língua espanhola. Para tanto, partimos da hipótese de que serão encontradas diferenças léxico-gramaticais, tendo em vista o distanciamento temporal entre a produção dos textos, mas principalmente formas distintas de construir ou apresentar o texto que se justifiquem no propósito das traduções e em seu público-alvo, o que a princípio parece 
resultar em elementos paratextuais divergentes e estruturas narrativas distintas. A seguir, daremos início ao estudo de caso, no qual poderemos observar os aspectos aqui elencados.

\section{Estudo de caso: "El Pato y la Serpiente"}

Analisaremos duas retextualizações interlinguais (espanhol-português) da fábula “El Pato y la Serpiente”, publicada pela primeira vez em Madri em 1782. Esta edição contém 67 fábulas em verso, compostas como narrativas em forma de poemas, mas nenhuma delas incorpora aos textos das fábulas a sentença moral que acompanha edições mais modernas. Nessa primeira publicação, as sentenças morais são apresentadas separadamente, num índice de fábulas e seus assuntos. Não constam imagens no interior do livro nem na capa. Uma advertência do editor é o único paratexto que antecede o início das fábulas. 0 sumário, onde estão incluídas as sentenças morais, é apresentado logo após o final da última fábula, seguido por um índice dos tipos de métrica adotados nas fábulas.

[ES-ES] EI Pato y la Serpiente (Madri, 1782)

Autor: Tomás de Iriarte

A orillas de un estanque

Diciendo estaba un Pato:

A qué animal dió el cielo

Los dones que me ha dado?

Soi de agua, tierra y aire:

Quando de andar me canso,

Si me antoja, vuelo,

Si me antoja, nado.

Una Serpiente astuta,

Que le estaba escuchando,

Le llamó con un silbo,

Y le dixo: Seo guapo,

No hai que echar tantas plantas;

Pues ni anda como el Gamo,

$\mathrm{Ni}$ vuela como el Sacre,

Ni náda como el Barbo:

$\mathrm{Y}$ así tenga sabido

Que lo importante y raro

No es entender de tódo,

Sinó ser diestro en algo.

Mas vale saber una cosa bien, que muchas mal.
[PT-PT] O pato, e a Serpente (Porto, 1796)

Tradutor: Romao Francisco Antonio Creyo

Junto á margem de hum lago

Dizendo eftava hum Pato,

A ninguém deo o Céo

Os dons que amim ha dado;

Sou d'agoa, terra, e ár,

Quando de andar me canço

Se me parece vô-o,

E quando quero nado.

Huma aftuta Serpente

Que o eftava efcutando,

Com hum filvo lhe diffe:

Naõ, naõ blazona tanto,

Pois inda que bazofia,

Naõ anda como o Gamo,

Nem vôa qual Milhafre,

Nem nada como o Barbo;

Naõ he faber de tudo

O importante, e raro,

Saber bem hum coufa

Eis-aqui todo o cafo. 
[PT-BR] O pato e a serpente (São Paulo, 1993). Tradutora: Nair Lacerda

Um pato muito vaidoso morava à beira de um lago. E consigo mesmo falava:

- Deus foi pródigo para comigo, mais do que para com qualquer outro animal. Sei caminhar, voar e nadar. Qual é o outro animal que assim goza as vantagens da terra, das águas e dos céus?

Uma serpente que por ali passava, ouviu-o, e deu-lhe uma lição:

- Não sejas tolo. Por que te gabas de andar sobre a terra se não podes correr como o gamo? Por que te ufanas de andar pelas águas se não és capaz de nadar como o delfim? E por que tanto gabas teu vôo se ele não se pode comparar ao da águia?

Mais vale fazer uma só coisa bem-feita do que muitas mediocremente.

O quadro apresentado traz o TF e os dois TAs, mantendo as convenções ortográficas tal qual figuram nas edições consultadas e adotando uma legenda que indica idioma e país de origem. Os textos analisados são:

[ES-ES] 1. ${ }^{a}$ edição espanhola de 1782, publicada em Madri (YRIARTE, 1782: 30-31); [PT-PT] edição portuguesa de 1796, publicada no Porto (YRIARTE, 1796: 37-38); e [PT-BR] edição brasileira de 1993, publicada em São Paulo (IRIARTE, 1993: 120-121).

\subsection{O Pato, e a Serpente [PT-PT]}

“O Pato, e a Serpente" é a Fábula XVIII do livro Fabulas Literarias (YRIARTE 1796), primeira tradução para o português europeu, realizada por Romaõ Francisco Antonio Creyo na cidade do Porto, em 1796. Traz os textos integrais (67 fábulas de Iriarte) e apresenta um índice das fábulas no início, sem incluir nele os "assuntos", mas apenas os títulos das fábulas. Incorpora uma dedicatória a D. Maria Izabel de Lencastre Cezar e Menezes e só depois desta inclui, traduzida para o português, a advertência posta pelo editor espanhol no frontispício da primeira impressão madrilenha das fábulas, sem as 6 linhas finais do texto original da advertência, que remetiam ao índice de tipos de métrica (já que este índice também está ausente na tradução portuguesa). Não constam imagens no interior do livro nem na capa.

Assim como as demais fábulas contidas nesse volume e como seu próprio TF, o TA se trata de uma narrativa em forma de poema. Tem 106 palavras (excetuado o título), pouco menos que o texto em espanhol, que tem 117 palavras (excetuados o título e a sentença moral, que não é apresentada junto ao texto). Dos seus 20 versos, 15 representam as vozes das personagens, 
enquanto 5 são ocupados pela voz narrativa - o que reproduz a distribuição de vozes do texto de Iriarte. Ocupa as páginas 30 e 31 dessa edição, com texto corrido, diagramado de forma muito semelhante à do TF. A sentença moral é suprimida, já que o volume não mantém o índice das fábulas e seus assuntos, não incorpora a sentença moral ao texto da fábula nem a apresenta em qualquer outro lugar do livro.

Reproduzimos o texto a seguir, com a mesma ortografia e os mesmos espaçamentos, acrescentando apenas a numeração das estrofes e dos versos para facilitar a referência a cada um deles ao longo da análise. Ao lado, repetimos o TF para que o leitor acompanhe mais facilmente os comentários e as comparações. 


\begin{tabular}{|c|c|c|}
\hline \multicolumn{3}{|c|}{$\begin{array}{c}\text { FABULA XVIII. } \\
\text { O PATO, E A SERPENTE. }\end{array}$} \\
\hline 1 & Junto á margem de hum lago & \multirow{4}{*}{ 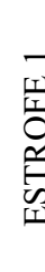 } \\
\hline 2 & Dizendo eftava hum Pato, & \\
\hline 3 & A ninguem deo o Céo & \\
\hline 4 & Os dons que amim ha dado ; & \\
\hline 5 & Sou d'agoa, terra, e ár, & \multirow{4}{*}{ 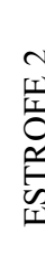 } \\
\hline 6 & Quando de andar me canço & \\
\hline 7 & Se me parece vô-o & \\
\hline 8 & E quando quero nado. & \\
\hline 9 & Huma aftuta Serpente & \multirow{4}{*}{ 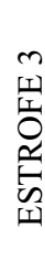 } \\
\hline 10 & Que o eftava efcutando, & \\
\hline 11 & Com hum filvo lhe diffe : & \\
\hline 12 & Naõ , naõ blazone tanto, & \\
\hline 13 & Pois inda que bazofia , & \multirow{4}{*}{ 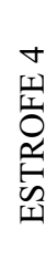 } \\
\hline 14 & Naõ anda como o Gamo, & \\
\hline 15 & Nem vôa qual Milhafre, & \\
\hline 16 & Nem nada como o Barbo ; & \\
\hline 17 & Naõ he faber de tudo & \multirow{4}{*}{$\begin{array}{l}n \\
\text { ㄸy } \\
0 \\
0 \\
\text { v } \\
n \\
\text { II }\end{array}$} \\
\hline 18 & O importante, e raro, & \\
\hline 19 & Saber bem hum coufa & \\
\hline 20 & Eis-aqui todo o cafo. & \\
\hline
\end{tabular}

\begin{tabular}{|c|c|c|}
\hline \multicolumn{3}{|c|}{$\begin{array}{c}\text { FÁBULA XIII } \\
\text { EL PATO Y LA SERPIENTE }\end{array}$} \\
\hline 1 & A orillas de un estanque & \multirow{4}{*}{ 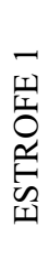 } \\
\hline 2 & Diciendo estaba un Pato: & \\
\hline 3 & ¿ A qué animal dió el cielo & \\
\hline 4 & Los dones que me ha dado? & \\
\hline 5 & Soi de agua, tierra y aire : & \multirow{4}{*}{ 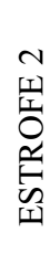 } \\
\hline 6 & Quando de andar me canso, & \\
\hline 7 & Si se me antoja, vuelo, & \\
\hline 8 & Si se me antoja, nado. & \\
\hline 9 & Una Serpiente astuta, & \multirow{4}{*}{ 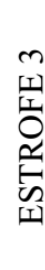 } \\
\hline 10 & Que le estaba escuchando, & \\
\hline 11 & Le llamó con un silbo, & \\
\hline 12 & Y le dixo : Seo guapo, & \\
\hline 13 & No hai que echar tantas plantas ; & \multirow{4}{*}{ 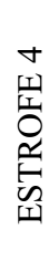 } \\
\hline 14 & Pues ni anda como el Gamo, & \\
\hline 15 & Ni vuela como el Sacre, & \\
\hline 16 & Ni náda como el Barbo : & \\
\hline 17 & Y así tenga sabido & \multirow{4}{*}{ 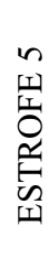 } \\
\hline 18 & Que lo importante y raro & \\
\hline 19 & No es entender de tódo, & \\
\hline 20 & Sinó ser diestro en algo. & \\
\hline
\end{tabular}

Quadro 2 - Reprodução da fábula “O Pato, e a Serpente” (1796) e seu TF. Fonte: elaborado pelas autoras (2017) a partir das fontes citadas.

O TA é todo construído com versos de 6 sílabas poéticas. Levando em conta a diferença no modo de contagem de sílabas poéticas entre as línguas portuguesa e espanhola - já que em português conta-se até a última sílaba tônica, desconsiderando-se o que vem a seguir, enquanto que em espanhol conta-se até a primeira sílaba após a tônica, acrescentando-se uma sílaba à contagem no caso da tônica ser a última -, podemos dizer que as 6 sílabas poéticas do texto em português coincidem com as 7 sílabas do texto em espanhol. 
Assim como seu TF, o TA divide-se em 5 estrofes de 4 versos cada uma e constrói em A_0 todas as suas rimas finais vocálicas entre os versos pares, do 2 ao 20, iniciadas pela última vogal tônica da palavra "Pato" (Pato, dado, canço, nado, efcutando, tanto, Gamo, Barbo, raro, calo). O texto em português mantém, ainda, a irregularidade nos acentos rítmicos do texto em espanhol, já que estes contam com algumas variações ao longo dos versos.

O início das estrofes 2 e 3 aparecem indicados tipograficamente por recuo de primeira linha no primeiro verso, o que não se repete nas estrofes 1,4 e 5, que começam alinhadas com os demais versos. 0 recuo de primeira linha é usado como padrão no TF, que abre mão do recuo apenas na primeira estrofe. Três estrofes e meia estão dispostas na página 30 e uma e meia, na página 31, igualmente por razões de espaço. A diagramação do texto e as fontes utilizadas nos textos fonte e alvo são muito semelhantes.

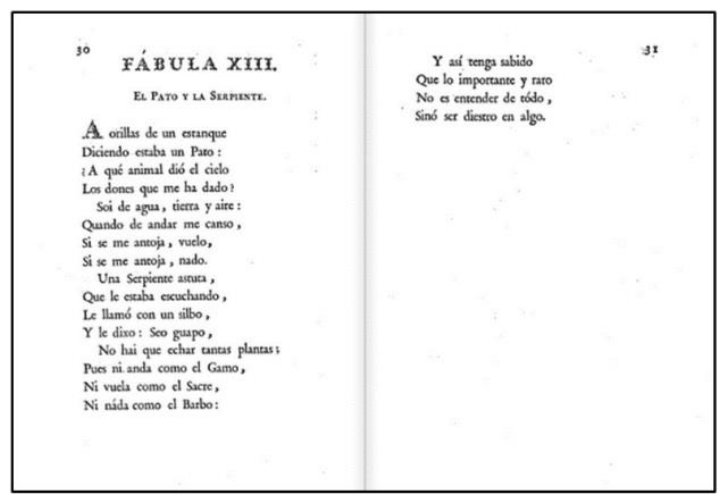

Figura 1 - A fábula "El Pato y la Serpiente" (1782). Fonte: web.

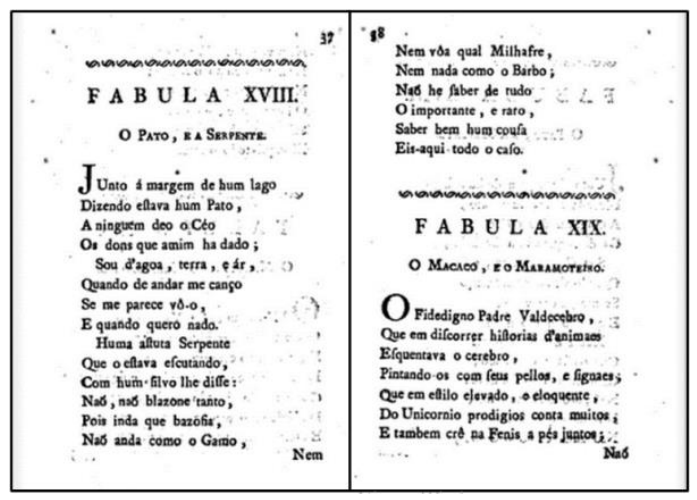

Figura 2 - A fábula "O Pato, e a Serpente" (1796). Fonte: web.

Ao que parece, há um erro tipográfico no verso 19, que não concorda o gênero do artigo com o substantivo (v. 19 Saber bem hum coula). A falta de concordância nominal ocasiona um único verso com métrica diferente, já que este conta apenas 5 sílabas poéticas, enquanto todos os outros contam 6 sílabas. Podemos presumir, portanto, que a falta de concordância não seja proposital, constituindo um erro tipográfico, comum nessa época de consolidação da imprensa.

A voz narrativa apresenta o espaço sucintamente, de forma semelhante à do TF, embora dê margem a uma interpretação mais ampla: o "estanque" do texto de 1782 , que pode ser entendido como um tanque ou reservatório, é 
retextualizado como um "lago" (v. 1 A orillas de un estanque $\rightarrow$ v. 1 Junto á margem de hum lago). 0 termo "estanque" é definido pelo dicionário da Real Academia Española como “1. m. Balsa construida para recoger el agua, con fines utilitarios, como proveer al riego, criar peces, etc., o meramente ornamentales", enquanto que o termo "lago" é definido pelo dicionário Aulete como "1. Geog. Extensão de água cercada de terra; 2. Tanque de água decorativo, em parque ou jardim”. Ou seja, passa de uma construção necessariamente criada pelo homem a uma outra que tanto pode ser artificial quanto natural, muito embora seja mais comumente entendida como um acidente geográfico natural.

Em consulta ao Tesoro Lexicográfico, identificamos 0 verbete "ESTANQUE" em um dicionário castelhano do século XVIII, publicado em Madri, em quatro volumes. Do segundo volume, identificado no site como “1787 TERREROS Y PANDO”, extraímos o verbete abaixo:

\section{ESTANQUE, depofito de agua, hecho, comunmente, con arte. Fr. Etang. Lat. Stagnum. It. Stagno.}

Figura 3 - Verbete "Estanque” no Dicionário Castellano de Terreros y Pando. Fonte: web.

Com isso, entendemos que mesmo à época da publicação o termo "estanque" servia para designar unicamente um tipo de construção humana, o que não abrange um lago natural. Independente disso, a possibilidade de mudança semântica provocada pela escolha do termo não parece produzir grande impacto na descrição do espaço, que não desempenha um papel relevante nem volta a ser mencionado no texto.

As personagens são nomeadas com substantivos comuns que designam suas espécies, ambos iniciados com letra maiúscula, assim como acontece no TF: o narrador nos apresenta o Pato (v. 2 Diciendo estaba un Pato $\rightarrow$ v. 2 Dizendo eftava hum Pato) e a Serpente (v. 9 Una Serpiente astuta , I v. 10 Que le estaba escuchando $\rightarrow$ v. 9 Huma aftuta Serpente | v. 10 Que o eftava efcutando). Essa apresentação não inclui qualquer descrição física, mas mantém a descrição psicológica da serpente, qualificada pelo narrador como astuta. As escolhas tradutórias, em cada caso, se mantêm tão próximas do texto em espanhol quanto possível. Contudo, tanto quanto à relação 
semântica quase linear, estabelecida a partir de microunidades do texto (palavras, sintagmas) - como a que vemos no v. 10 -, nesta retextualização deixa-se ver como prevalente a relação estabelecida com as características da forma poética - tipo e localização de rimas, número de sílabas poéticas, de versos, de estrofes. De modo que sua característica poderia ser formulada como uma busca de equilíbrio entre essas duas prioridades - linearidade semântica e reprodução da forma composicional -, prevalecendo a forma de composição quando não é possível atender a ambos os níveis de equivalência. Isso explicaria deslocamentos de unidades entre um verso e outro, algumas omissões, acréscimos e modificações, exemplificados a seguir.

$\mathrm{Na}$ primeira estrofe, a primeira fala do pato, que no TF é uma interrogativa, no TA é transformada em afirmativa (v. 3 ¿ A qué animal dió el cielo | v. 4 Los dones que me ha dado ? $\rightarrow$ v. 3 A ninguem deo o Céo | v. 4 Os dons que amim ha dado). 0 questionamento do pato pode ser entendido como uma pergunta retórica, que visa a criar um efeito enfático, e não obter uma resposta - até porque não se dirige a um destinatário específico, dado que nesse momento o pato fala consigo mesmo e para quem queira ouvi-lo. A escolha tradutória parece se justificar na adequação métrica dos versos, já que uma tradução literal do verso 4 resultaria em uma sílaba poética a menos e o efeito produzido pela afirmativa, nesse caso, não parece provocar mudança relevante na construção da narrativa. Assim como no caso do v. 17, examinado mais adiante, a modificação opera sobre um elemento de importância mais secundária do TF.

Nessa mesma fala inicial do pato, percebemos que uma palavra mais foi grafada com inicial maiúscula na retextualização: “Céo", que no texto de 1782 aparece como "cielo". Dentre 8 acepções possíveis apresentadas pelo dicionário Priberam para o verbete "céu", que é a grafia atual da palavra portuguesa, destacamos a seguinte: "6. Providência divina. (Geralmente com inicial maiúscula)", que coincide com a acepção mais provável da palavra castelhana dentre as possibilidades elencadas pelo dicionário da Real Academia Española: “5. m. Dios o su providencia”. 0 uso de maiúscula, nesse caso, não parece provocar mudança na construção de sentido, já que a maiúscula inicial 
parece se tratar de uma convenção da língua portuguesa que não implica em diferença semântica entre os termos em um e outro idioma.

A ordem com que as informações são apresentadas por vezes se altera os deslocamentos referidos anteriormente -, o que também parece atender a questões formais. Assim, pode-se observar o deslocamento de elementos entre os versos, para cima ou para baixo, como se percebe no exemplo a seguir, que reproduz a última estrofe dos textos alvo e fonte:

$17 \quad$ Y así tenga sabido

18 Que lo importante y raro

19 No es entender de tódo,

20 Sinó ser diestro en algo.
Naõ he laber de tudo

O importante, e raro, Saber bem hum coula

Eis-aqui todo o calo.

$\mathrm{Na}$ estrofe acima, também se percebe a reformulação do verso 17 do texto espanhol, que é retextualizado no verso final do texto português. Nessa estrofe, o TF usa uma subordinada adversativa na forma “no... sino”, que, em sua estrutura lógica, implica a negação absoluta da veracidade do primeiro termo para substituí-lo pelo que se afirma como verdadeiro no segundo termo, pressupondo que esta última afirmação seria logicamente incompatível com a primeira. Nessa estrutura, nega-se absolutamente "entender de todo" como importante, para afirmar "ser diestro en algo" em seu lugar, como conclusão final do diálogo entre as personagens. Assim, no TF a moral defendida pela serpente a modo de conclusão aponta algo que o pato tem o dever de saber (tenga sabido). No TA, em lugar de "tenga sabido", que representa algo que o pato deveria saber, a serpente diz que é esse "todo o caso", o que parece mais neutro e dirigido ao público-leitor.

Para falar do pato que se gaba de suas pretensas qualidades, o texto em espanhol usa a expressão "echar plantas”, que significa lançar bravatas ou ameaças e já caiu em desuso atualmente. Em português, usou-se o verbo “blasonar” (com Z, na grafia da época) para essa locução verbal. "Blasonar” é vangloriar-se, atribuir-se qualidades que não se têm, e igualmente caiu em desuso. Na mesma estrofe, a serpente trata o pato por “guapo", que como vocativo pode expressar carinho, irritação ou desprezo, a depender do tom adotado, e no contexto parece tratar-se do último caso. No mesmo campo 
semântico de "echar plantas" (como "lançar bravatas"), em dicionário da época (TERREROS Y PANDO, 1787), encontramos "guapería" com o sentido de “jactancia”, ou seja, "alabanza propia, desordenada y presuntuosa”:

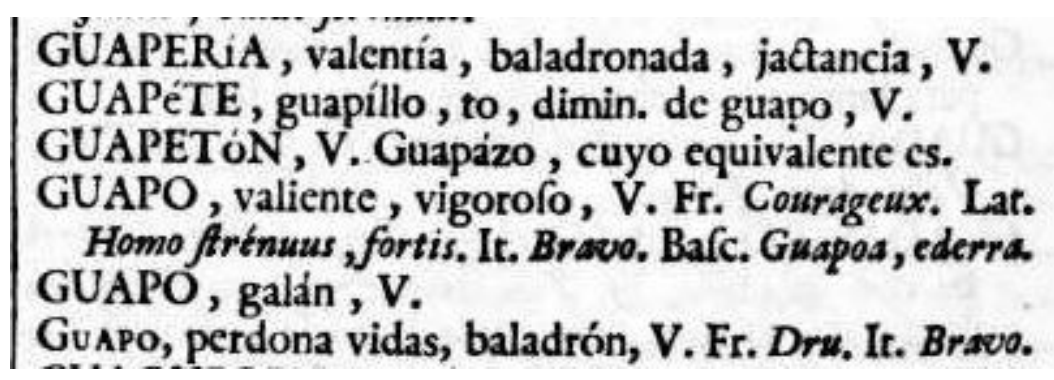

Figura 4 - Verbete “Guapo" e correlacionados no Dicionário de Terreros y Pando. Fonte: web.

O TA troca o vocativo "seo guapo" por um substantivo: "bazófia" (sem acento, na grafia da época), usado em Portugal no sentido de fanfarrão, alguém que se vangloria de valentias falsas ou exageradas. Ou seja, na retextualização a ideia de gabar-se injustificadamente é reforçada com essa escolha lexical.

11 Le llamó con un silbo,

12 Yle dixo : Seo guapo,

13 No hai que echar tantas plantas;

14 Pues ni anda como el Gamo,

15 Ni vuela como el Sacre,

16 Ni náda como el Barbo :
Com hum filvo lhe difle : Naõ , naõ blazone tanto , Pois inda que bazofia , Naõ anda como o Gamo , Nem vôa qual Milhafre , Nem nada como o Barbo ;

Os animais mencionados na estrofe 4 também merecem ser mencionados: "el gamo", "el sacre” e "el barbo". "Gamo" é um tipo de veado, animal comum na Europa e incomum na América do Sul. Em português, poderia ser traduzido como "gamo", "veado" ou “cervo", sendo as duas últimas opções mais genéricas - referem-se a cerca de 40 tipos de cervídeos, dentre eles, o gamo. Na retextualização, manteve-se “gamo", nome provavelmente bem conhecido em Portugal. "Sacre" refere-se ao falcãosacre, espécie de ave de rapina europeia. O TA escolheu em seu lugar "milhafre", ave de rapina endêmica da região dos Açores, em Portugal. Essa escolha não parece ter sido motivada por necessidades rímicas, já que o efeito 
conseguido com "não voa como o sacre" é equivalente ao alcançado por "não voa qual milhafre". E "barbo" é um peixe europeu, também pouco conhecido na América do Sul. A tradução manteve a escolha, já que o barbo é igualmente frequente na Espanha e em Portugal. Ou seja, o TF menciona três animais europeus que foram traduzidos por animais também europeus, mantendo-se dois iguais (gamo e barbo) e um semelhante (sacre/milhafre, aves de rapina). As escolhas parecem próprias para o leitor português da época, embora possam se configurar como um obstáculo para o leitor brasileiro contemporâneo, principalmente um leitor mirim.

Quanto aos níveis de linguagem, a presença de arcaísmos é ainda mais marcante que no texto em espanhol. As marcas mais notáveis são o uso do $\mathrm{S}$ longo ( () , variante do $S$ minúsculo que era usado em sua substituição quando este ocorria no meio ou no começo de uma palavra (como em aftuta, filvo e difre); o uso de h em palavras como hum (em lugar de um), huma (em lugar de uma) e he (em lugar de é); o uso antigo do ditongo "ou", como em coufa (em lugar de coisa); as grafias obsoletas de palavras como deo, amim, Céo, agoa e vô-o (em vez de deu, a mim, Céu, água e voo); e a acentuação gráfica distinta, como em naõ, á, ár e vôa (em lugar de não, à, ar e voa).

Os padrões gramaticais são semelhantes, o que possivelmente se justifica pela proximidade idiomática, geográfica e temporal entre TF e TA. 0 uso da ordem indireta é frequente em ambos os textos e ocorre de forma bem similar, com uma pequena variação na última estrofe, em que um trecho escrito na ordem direta foi retextualizado em ordem indireta (certamente, para melhor acomodação dos versos em língua portuguesa):

$17 \quad Y$ así tenga sabido

18 Que lo importante y raro

19 No es entender de tódo,

20 Sinó ser diestro en algo.
Naõ he faber de tudo

0 importante, e raro, Saber bem hum coula

Eis-aqui todo o calo.

Podemos dizer, por fim, que as adaptações identificadas na retextualização analisada parecem ser todas pontuais, com vistas principalmente a atender necessidades formais do texto poético, e ainda permitem que o TA seja identificado como uma tradução interlingual do TF. $\mathrm{E}$, por sua grande aproximação do TF - apresentação gráfica similar, 
manutenção da métrica, mesma distribuição de vozes, níveis de linguagem semelhantes -, essa retextualização tende para o polo da adequação.

\section{2. "O pato e a serpente" [PT-BR]}

"O pato e a serpente" é a última das 4 fábulas de Iriarte contidas no livro Fábulas do Mundo Inteiro (LACERDA 1993), parte da coleção Clássicos da Infância do Círculo do Livro. Consta o nome de Nair Lacerda como tradutora e organizadora. 0 volume inclui fábulas de 12 autores e ainda outras de autoria desconhecida. É apresentado explicitamente como uma antologia de fábulas, por meio do nome do volume. Traz prefácio da tradutora, que foi também responsável pela seleção dos textos, e notas sobre os autores traduzidos. Não mantém a advertência do editor nem nenhum dos outros metatextos presentes na edição espanhola de 1782. Constam imagens no interior do livro e na capa.

Assim como as demais fábulas contidas nesse volume, o TA é uma narrativa em forma de prosa. Apresenta a sentença moral incorporada ao texto, logo após o término da fábula, com destaque em itálico. 0 texto tem 125 palavras (excetuado o título e incorporada a sentença moral), praticamente o mesmo que seu TF, que tem 126 palavras (contando com a sentença moral, que não é apresentada junto ao texto; sem ela, são 117 palavras). Das 125 palavras do TA, 88 representam o diálogo entre o pato e a serpente, enquanto 37 representam a voz narrativa - na fábula de 1782 , o diálogo também representa 88 das 126 palavras, enquanto o narrador dá conta das outras 38. Portanto, percebe-se que, embora ocorra a passagem de verso para prosa e de um idioma a outro, o tamanho do texto e a distribuição das vozes ocorre de forma praticamente idêntica. Em ambos os textos, o diálogo entre os protagonistas ocupa a maior parte da narrativa, com mais que o dobro do total de palavras do narrador. Esse dado, em conjunto com a informação bibliográfica que identifica Nair Lacerda como tradutora (e não adaptadora), permite construir a expectativa de que estejamos diante de uma tradução interlingual, o que só poderemos comprovar ou refutar após uma análise no micronível. 
O texto é corrido e diagramado abaixo do texto visual, ocupando mais que a metade da página 120. Como resultado de uma diagramação que parece não aproveitar bem o espaço da página (o que se constata ao observar a diagramação das demais páginas do livro, que não apresentam padrão semelhante), a sentença moral fica isolada na página 121. Uma ilustração ocupa a outra metade da página 120, e o restante da página 121 fica em branco. Como é um livro ilustrado, predomina o texto escrito e a ilustração acompanha a narrativa, reiterando o que está dito com palavras. A única imagem que ilustra a história não tem margem ou moldura, aparece livre na página. É feita a modo de croqui, em preto e branco. As informações paratextuais da capa (imagem de uma criança) e da coleção (Clássicos da Infância), no entanto, indicam claramente que o público-alvo dessas fábulas é o infantil. 0 formato do livro é vertical e a enunciação gráfica, que pode ser entendida como a forma do texto, é convencional. A fonte utilizada é Times New Roman e os tipos gráficos são todos pretos.

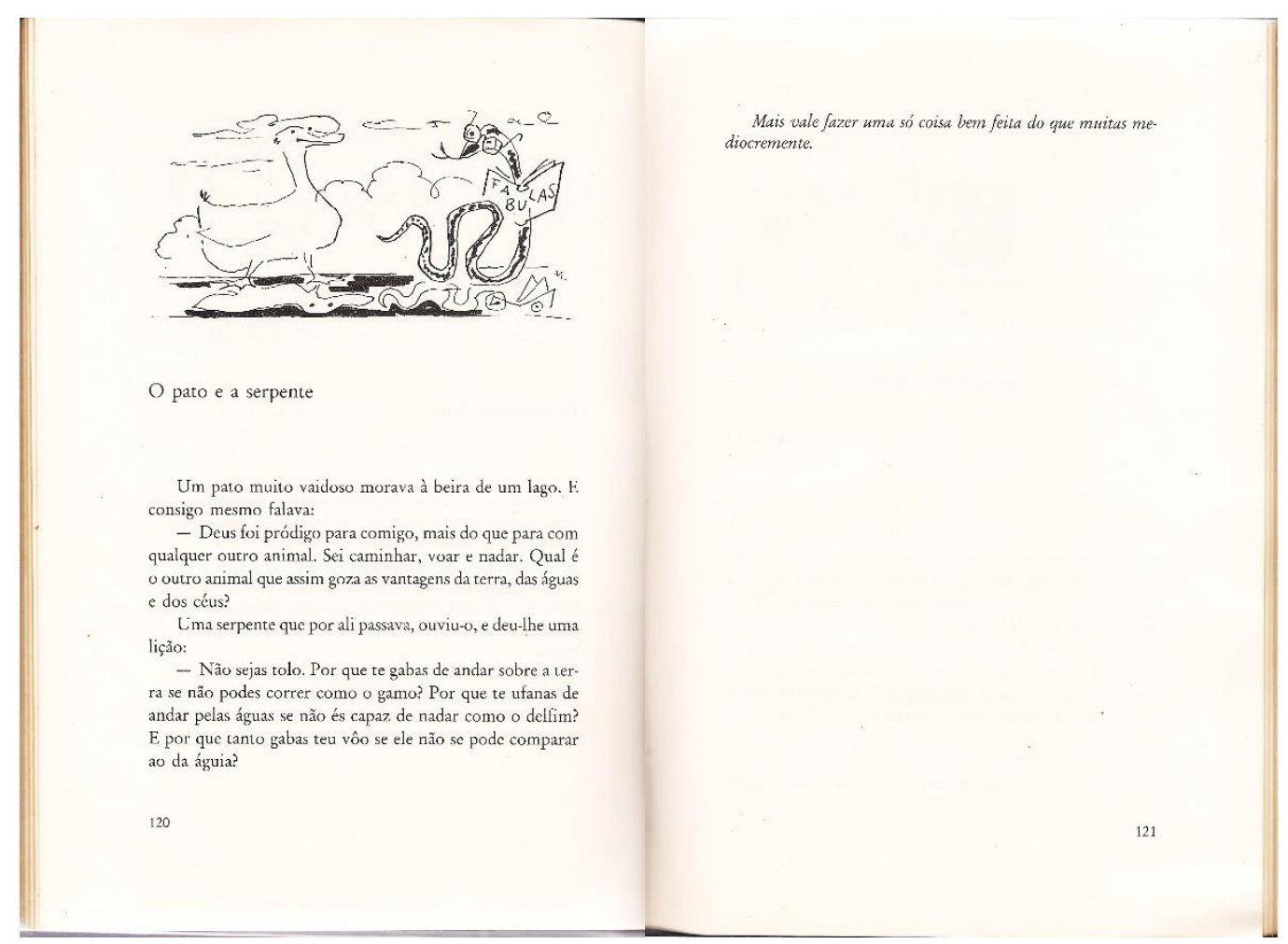

Figura 5 - A fábula "O pato e a serpente” (1993). Fonte: acervo pessoal da autora. 
Reproduzimos o texto a seguir:

\section{O PATO E A SERPENTE}

Um pato muito vaidoso morava à beira de um lago. E consigo mesmo falava:

— Deus foi muito pródigo para comigo, mais do que para com qualquer outro animal. Sei caminhar, voar e nadar. Qual é o outro animal que assim goza as vantagens da terra, das águas e dos céus?

Uma serpente que por ali passava, ouviu-o, e deu-lhe uma lição:

- Não sejas tolo. Por que te gabas de andar sobre a terra se não podes correr como o gamo? Por que te ufanas de andar pelas águas se não és capaz de nadar como o delfim? E por que tanto gabas teu vôo se ele não se pode comparar ao da águia?

Mais vale fazer uma só coisa bem feita do que muitas mediocremente.

Quadro 3 - Reprodução da fábula "O pato e a serpente" (1993).

Fonte: elaborado pelas autoras (2017) a partir da fonte citada.

O narrador dá início ao relato apresentando o protagonista e o espaço. O primeiro elemento - o protagonista - é construído de forma distinta no TA em relação ao TF: a personagem é nomeada por um substantivo comum grafado com inicial minúscula (pato) e acompanhado de um adjetivo de conotação negativa (vaidoso), intensificado por um advérbio de intensidade (muito), enquanto que no TF o pato é grafado com inicial maiúscula e não recebe adjetivações por parte do narrador (v. 1 A orillas de un estanque | v. 2 Diciendo estaba un Pato $\rightarrow$ Um pato muito vaidoso morava à beira de um lago).

O segundo elemento - o espaço - é construído de forma muito semelhante ao TF, mas, assim como acontece com o texto português de 1796, o "estanque", que pode ser entendido como um tanque ou reservatório - ou seja, uma construção necessariamente criada pelo homem - é retextualizado como um "lago", que tanto pode ser artificial quanto natural, muito embora seja mais comumente entendido como um acidente geográfico natural. Independente disso, também nessa retextualização, a possibilidade de mudança semântica provocada pela escolha do termo não parece produzir 
grande impacto na descrição do espaço, embora este apresente um papel mais relevante nesta retextualização que no TF e na tradução portuguesa, além de voltar a ser mencionado nas falas do pato e da serpente.

Em sua fala, o pato estabelece uma ligação entre as atividades que diz desempenhar e o ambiente em que essas atividades são realizadas, relacionando as ações de caminhar, voar e nadar a gozar as vantagens da terra, das águas e dos céus, não respectivamente (Sei caminhar, voar e nadar. Qual é o outro animal que assim goza as vantagens da terra, das águas e dos céus?). Já a serpente acrescenta outro item na relação atividade/ambiente, incluindo aí um animal para cada par (Por que te gabas de andar sobre a terra se não podes correr como o gamo? Por que te ufanas de andar pelas águas se não és capaz de nadar como o delfim? E por que tanto gabas teu vôo se ele não se pode comparar ao da águia?). Nas comparações que faz, a serpente tanto desdenha o desempenho do pato que descreve seu nado como "andar pelas águas", em oposição ao delfim, que nada. 0 céu não chega a ser mencionado pela serpente, que, em vez de citar o ambiente, transforma a ação de voar em um substantivo (o vôo) que subentende o espaço.

Ainda na fala da serpente, observamos a reiteração de uma fórmula: “Por que --- se não --- , por que --- se não ---, e por que --- se não ---", uma reestruturação da fórmula usada no TF: "No hai que --- , pues ni --- , ni --- , ni -.-" (v. 13 No hai que echar tantas plantas ; I v. 14 Pues ni anda como el Gamo, I v. 15 Ni vuela como el Sacre , | v. 16 Ni náda como el Barbo $\rightarrow$ Por que te gabas de andar sobre a terra se não podes correr como o gamo? Por que te ufanas de andar pelas águas se não és capaz de nadar como o delfim? E por que tanto gabas teu vôo se ele não se pode comparar ao da águia?). Tal reformulação, além de estender a fala da serpente, transforma afirmativas em interrogativas. Assim, o que antes a serpente dizia em forma de constatação, passa a ser textualizado como uma indagação - o que, em conjunto com a supressão da última estrofe do texto de 1782, na qual a serpente apresentava seu julgamento, acaba por minimizar o caráter corretivo de sua fala.

Assim como o pato, a serpente é apresentada por meio de um 
substantivo comum iniciado com minúscula, mas não recebe adjetivação - à diferença do TF, em que o narrador qualifica a serpente como astuta, um adjetivo de conotação positiva (v. 9 Una Serpiente astuta, | v. 10 Que le estaba escuchando $\rightarrow$ Uma serpente que por ali passava, ouviu-o). Como resultado, a serpente não mais parece autorizada pelo narrador, que se mostra totalmente neutro em relação a ela. Em contrapartida, o pato, já qualificado pelo narrador como vaidoso, é adjetivado pela serpente como tolo, o que estabelece uma relação tradutória com o "Seo guapo" do TF, aproximando a escolha lexical em português da expressão de desprezo possível para esse vocativo em espanhol (v. 12 [...] Seo guapo | v. 13 No hai que echar tantas plantas $\rightarrow$ Não sejas tolo). Ainda com relação às escolhas lexicais, observamos que a expressão "echar plantas" é desmembrada em dois verbos: "gabar-se", com duas ocorrências, e "ufanar-se", com uma ocorrência. Ambos podem ser interpretados como sinônimos de "vangloriarse", o que corresponde ao sentido construído a partir da expressão usada no TF, mas sua reiteração em três ocorrências acaba por enfatizá-la. Com isso, a vaidade entra como tema de forma mais marcante e explícita nessa retextualização.

$\mathrm{Na}$ ilustração, a serpente ganha certo destaque: o grau de humanização observado nas personagens retratadas resume-se ao uso de objetos humanos, e a serpente aparece usando um par de óculos e segurando um livro de fábulas, com ares de intelectual, enquanto que o pato parece apenas um pato comum, sem características antropomorfizantes.

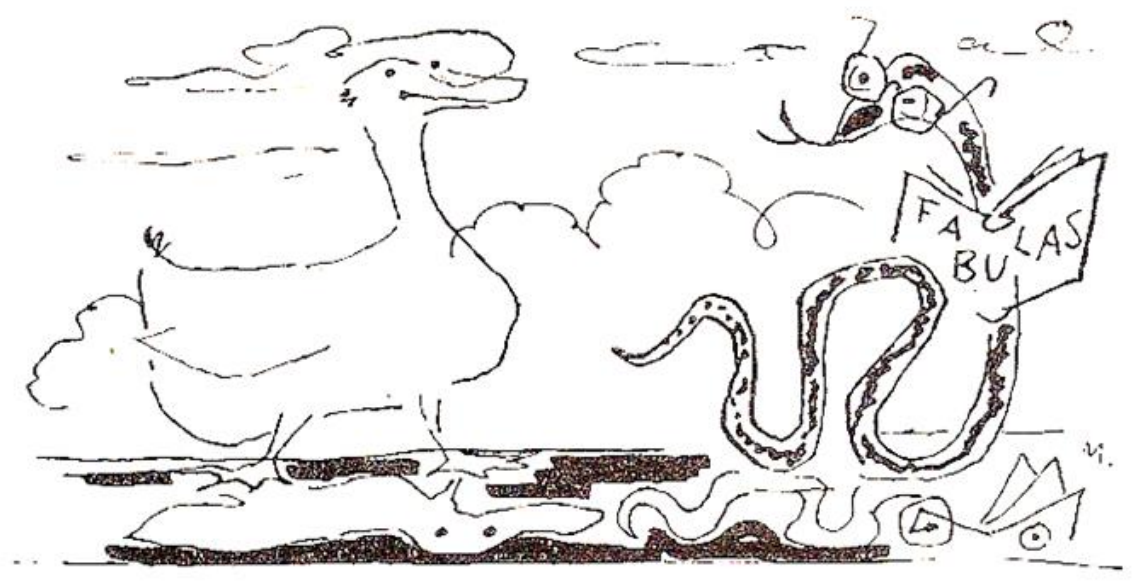


Figura 6 - Ilustração da fábula “O pato e a serpente” (1993).

Fonte: acervo pessoal da autora.

Os animais mencionados pela serpente não apresentam novidade, mas merecem comentário: o "gamo" em espanhol mantém-se "gamo" em português, denominação pouco conhecida no Brasil. Já o falcão "sacre" transforma-se em "águia" - também uma ave de rapina, esta sim bem conhecida no Brasil. E o peixe "barbo", desconhecido em terras tupiniquins, dá lugar ao "delfim" - uma denominação para golfinhos incomum no português brasileiro. Desse modo, ao passo que o texto parece querer aproximar-se do público-alvo ao usar animais que sejam mais conhecidos no Brasil, as escolhas de "gamo" e "delfim" em detrimento de alternativas possíveis, semanticamente semelhantes (como "veado" e "golfinho"), não parecem atender muito bem a esse propósito e talvez busquem alcançar um outro objetivo, que seria uma linguagem poética.

Nesta retextualização a última estrofe desaparece. Dado que seu conteúdo coincide basicamente com a sentença moral, ao que parece considerou-se suficiente manter apenas esta última, o que resulta em uma transferência do julgamento, que passa da voz da serpente no TF ( $Y$ así tenga sabido | Que lo importante y raro | No es entender de tódo, I Sinó ser diestro en algo) para a voz do narrador no TA (Mais vale fazer uma só coisa bem feita do que muitas mediocremente). Essa sentença moral se aproxima muito daquela que consta no índice das fábulas e seus assuntos do livro de 1782 (Más vale saber una cosa bien, que muchas mal).

O nível da linguagem mantém-se alto, com notável uso de linguagem poética, apesar da passagem de verso para prosa. As construções sintáticas e o vocabulário, ainda que difiram do TF, parecem estilisticamente tão elaborados quanto ele, como se observa na fala do pato (v. 3 ¿ A qué animal dió el cielo | v. 4 Los dones que me ha dado ? | v. 5 Soi de agua, tierra y aire $\rightarrow$ Sei caminhar, voar e nadar. Qual é o outro animal que assim goza as vantagens da terra, das águas e dos céus?) e também na da serpente (v. 13 No hai que echar tantas plantas ; | v. 14 Pues ni anda como el Gamo, | v. $15 \mathrm{Ni}$ vuela como el Sacre , I v. $16 \mathrm{Ni}$ náda como el Barbo $\rightarrow$ Por que te gabas de andar sobre a terra se não podes correr como o gamo? Por que te ufanas de andar pelas águas se não és capaz de nadar como o delfim? E por que tanto 
gabas teu vôo se ele não se pode comparar ao da águia?).

Ainda quanto aos níveis de linguagem, não identificamos a presença de arcaísmos observada na retextualização portuguesa: a grafia, a sintaxe e o vocabulário são atualizados para a época de publicação (1993) e atuais ainda para um leitor contemporâneo (2018). Contudo, esta retextualização não parece se preocupar em manter seu vocabulário e suas formulações sintáticas dentro do domínio cognitivo de seu público-alvo, o que geralmente se faz com frases curtas e léxico acessível mas não se verifica neste caso analisado - a exemplo de um trecho já citado da fala da serpente (Por que te ufanas de andar pelas águas se não és capaz de nadar como o delfim?), que tem 17 palavras, usa um verbo pronominal de modalidade culta (ufanar-se), adota uma figura de linguagem para referir-se a um nado desajeitado (andar pelas águas), escolhe uma designação pouco usada para "golfinho" (delfim) e usa a segunda pessoa do singular com a conjugação verbal correta (tu). Também os tipos gráficos correspondem ao que geralmente se adota para leitores experientes: o tamanho da fonte utilizada é pequeno e seu estilo é Times New Roman.

O grande número de modificações de escolhas lexicais, sintáticas e estilísticas acaba por dar o tom do conjunto global da retextualização de Nair Lacerda. Identificamos reformulações sintáticas, escolha de espécies de animais mais localizadas culturalmente para o público-alvo e omissão do julgamento oferecido pela serpente. Embora o tamanho do texto e a distribuição de vozes permaneçam praticamente idênticos, a construção do texto siga uma sequenciação semântica comparável dos componentes mais globais da narrativa, o nível da linguagem se mantenha, a linguagem poética dialogue com o texto de Iriarte e a sentença moral aproxime-se da que consta no livro de 1782 bem mais "palavra por palavra" que o restante do texto que a antecede, entendemos essa retextualização como uma adaptação interlingual.

A análise de paratextos permite identificar como público-alvo o infantil, mas essa não parece ser a preocupação dominante no corpo textual deste TA, aparentemente muito mais centrado em manter a poesia na linguagem prosaica que em manter seu léxico e suas construções sintáticas 
dentro do domínio cognitivo de seu público-alvo. Considerando suas modificações de léxico e sintaxe sistemáticas e, ao mesmo tempo, sua aproximação do TF em outros aspectos - apresentação gráfica sóbria, mesmo tamanho, mesma distribuição de vozes, níveis de linguagem semelhantes -, é possível entender que o TA se localiza em uma posição intermediária no continuum adequação/aceitabilidade. Tende para o polo da adequação no que se refere à sequenciação dos elementos básicos dos textos narrativos: voz narrativa ao início, primeira fala direta do pato seguida da voz da serpente, em mesmo número, com atos de fala comparáveis em cada fala, mesmas personagens, mesmas ações e mesma configuração entre protagonistaantagonista, moral do texto coincidente. Tende para o distanciamento do TF nas escolhas de léxico, de estruturas sintáticas, de coesão, de recursos estilísticos e padrões retóricos, o que leva a retextualização para o polo da aceitabilidade na relação entre os autores e suas escolhas, considerando o esquema comunicativo - A1 (Iriarte) । A2 (Nair Lacerda) -, já que mostra forte prevalência das escolhas de Nair Lacerda em todos os níveis microtextuais mencionados.

\section{Considerações finais}

Nas análises apresentadas, pudemos perceber que a retextualização portuguesa mantém o texto em verso, privilegia as características estéticas (versificação) da fábula de Iriarte e se aproxima muito do TF, o que faz com que esteja mais voltada para o polo da adequação. 0 texto não mostra marcas que indiquem direcionamento específico a público infantil, o que é coerente com a própria noção de que a literatura infantil viria a reconfigurar-se mais tarde e suas características modernas devem muito a recursos gráficos que são recentes, como a possibilidade da impressão em cores. Por suas características dominantes, identificamos essa retextualização como uma tradução interlingual.

Já a retextualização interlingual de Nair Lacerda se apresenta como um 
caso mais difícil para classificação, por estar situada em uma posição intermediária no continuum adequação/aceitabilidade e por realizar adaptações pontuais que afetam a construção da narrativa de formas pouco evidentes. Como resultado da análise, entendemos que o TA tende para o polo da adequação no que se refere à sequenciação dos elementos básicos dos textos narrativos e para o polo da aceitabilidade na relação entre os autores e suas escolhas. E, apesar de ter como público-alvo declarado o infantil, essa não parece ser a preocupação principal da retextualização brasileira, que aparenta preocupar-se muito mais em manter a linguagem poética que em manter seu léxico e suas construções sintáticas dentro do domínio cognitivo de um leitor mirim. Por suas características dominantes, identificamos essa retextualização como uma adaptação interlingual.

O estudo apresentado faz parte de uma pesquisa maior (RosAS 2017) que investigou retextualizações de quatro fábulas de Iriarte em português e espanhol. Além de dar visibilidade a um autor pouco estudado no Brasil e contribuir para as discussões sobre o gênero 'fábula', a pesquisa ajuda a esclarecer as linhas que diferenciam uma tradução de uma adaptação, vistas como formas de retextualização que alcançam o texto de forma global, e demonstra o percurso que as retextualizações das fábulas de Iriarte seguiram ao longo do tempo, em relação com seus sistemas de chegada e seu públicoalvo em seus contextos históricos.

\section{Referências bibliográficas}

ARIÈs, P. História Social da Criança e da Família. Tradução de Dora Flasksman. 2. ed. Rio de Janeiro: LTC - Livros Técnicos e Científicos, 1981.

BASTIN, G. Adaptation. In: Baker, M.; Saldanha, G.a (org.). Routledge Encyclopedia of Translation Studies. London/New York: Routledge, 2009 [1997].

Genette, G. Paratextos editoriais. Tradução de Álvaro Faleiros. São Paulo: Ateliê, 2009 [1987].

IRIARTE, T. O pato e a serpente. In: Lacerda, N. (seleção, introdução e tradução parcial). Fábulas do mundo inteiro. São Paulo: Círculo do Livro, 1993, pp. 120-121. (Coleção Clássicos da Infância) 
Lajolo, M.; zILBERMAn, R. A Literatura Infantil Brasileira: História \& Histórias. 2. ed. São Paulo: Ática, 1985.

LAMBERT, J.; VAN GORP, H. Sobre a descrição de traduções. Tradução de MarieHélène Catherine Torres e Lincoln Paulo Fernandes. In: Guerini, A.; Torres, M. H. C. e Costa, W. C. (org.). Literatura e tradução: textos selecionados de José Lambert. Rio de Janeiro: 7Letras, 2011 [1985], pp. 208-223.

RosAS, C. As fábulas de Tomás de Iriarte ao longo do tempo: um estudo descritivo de retextualizações em português e espanhol. Dissertação de mestrado. Orientadora: Cintrão, H. 276 pp. São Paulo: Tradusp, 2017.

SANDERS, J. Adaptation and appropriation. New York: Routledge, 2006.

TERREROS Y PANDO, E. Diccionario castellano con las voces de ciencias y artes y sus correspondientes en las tres lenguas francesa, latina e italiana. Tomo segundo. Madrid: Imp. Viuda de Ibarra, 1787. Disponível em: <ntlle.rae.es/ntlle/SrvltGUISalirNtlle>. Acesso em: 12 set. 2017.

TOURY, G. Descriptive Translation Studies and Beyond. Amsterdã-Filadélfia: Benjamins, 1995.

YRIARTE, T. O Pato, e a Serpente. In: Yriarte, T. Fabulas Literarias. Tradução de Romao Francisco Antonio Creyo. Porto: Officina de Viuva Mallen, Filhos, e Companhia, 1796, pp. 37-38. Disponível em: $<$ https://books.google.com.br/ books?id=H-8AAAAAMAAJ\&hl=ptBR\&pg=PR10\#v=onepage\& $q \& f=$ false $>$. Acesso em: $08 \mathrm{fev} .2017$.

YRIARTE, T. El Pato y la Serpiente. In: Yriarte, T. Fábulas Literarias. Madri: Imprenta Real, 1782, pp. 30-31. Disponível em: <https: / /books.google.com.br/books?id=NfpFAAAAcAA J\&hl=ptBR\&pg=PP7\# $v=$ onepage\&q\&f $f=$ false $>$. Acesso em: 08 fev. 2017. 